(3)

Volume 20, 2017

\title{
TECHNOLOGY AdDiCTION: How SOCIAL NETWORK SITES IMPACT OUR LIVES
}

\author{
Natalie Gerhart \\ Creighton University, Omaha, NB, USA \\ nataliegerhart@,creighton.edu
}

\section{ABSTRACT}

Aim/Purpose

The media and research have made significant noise about young people's addictions to technology, however the American Psychological Association (APA) has reserved judgment on the clinical diagnosis of technology addiction. Research to understand technology addiction is important to the future of information systems development and behavioral usage understanding.

Background Addiction implies that there is a problem from which an IS client needs to try to recover, further implying a negative impact on life. Multiple definitions and outcomes of addictions have been studied in the information systems discipline, with virtually no focus on quality of life of the IS client.

Methodology This research employs a survey of students at a large southwestern United States university. Measures were adopted from previously validated sources. The final sample includes 413 usable responses analyzed using PLS.

Contribution This research broadens theoretical and practical understanding of SNS IS client perceptions by relating technology addiction to a broader impact on an individual's life. By doing so, it provides guidance on society's understanding of frequent technology use, as well as the development of new systems that are highly used.

Findings This research indicates diminished impulse control, distraction, social influence and satisfaction are all highly correlated with technology addiction; specifically, $55 \%$ of the variance in addiction is explained by these four indicators. However, the model further shows addiction has no significant relationship with overall satisfaction of life, indicating that IS clients do not correlate the two ideas.

Recommendations Heavy technology use may indicate a paradigm shift in how people interact, for Practitioners instead of a concern to be addressed by the APA.

Recommendation for Researchers

Research needs to clearly define technology dependence, addiction, and overuse so that there is a strong understanding of what is meant. These findings help guide assumptions about the dark side of Information Technology.

Accepting Editor Raafat Saadé | Received: March 21, 2017 | Revised: July 8, 2017 |

Accepted: August 31, 2017.

Cite as: Gerhart, N. (2017). Technology addiction: How social network sites impact our lives. Informing Science: the International Journal of an Emerging Transdiscipline, 20, 179-194. Retrieved from http://www.informingscience.org/Publications/3851

(CC BY-NC 4.0) This article is licensed to you under a Creative Commons Attribution-NonCommercial 4.0 International License. When you copy and redistribute this paper in full or in part, you need to provide proper attribution to it to ensure that others can later locate this work (and to ensure that others do not accuse you of plagiarism). You may (and we encourage you to) adapt, remix, transform, and build upon the material for any non-commercial purposes. This license does not permit you to use this material for commercial purposes. 
Impact on Society While technology use is increasing, younger generations may find the use to be acceptable and less of a problem then older generations.

Future Research Future research should replicate these findings on other technology artifacts and other technology addiction definitions. In the future, there is also opportunity to delve deeper into the outcome variable of satisfaction with life.

Keywords addiction, satisfaction with life, social network sites, dependence

\section{INTRODUCTION}

As technology empowers humans to achieve many unthinkable things, it is also seen as the cause of several problems in society. Popular media often covers news stories discussing the narcissism associated with heavy use of social networks and describe an addiction that young people live with today (Augenbraun, 2014). Some professional help resources are accepting patients for self-diagnosed addictions to technology, such as Google Glass (J. Wilson, 2014). Researchers recognize the negative perceptions of technology and have conducted some qualitative documentation of the negative impact of smartphones on relationships within families (Vaghefi \& Lapointe, 2014). Despite the controversial nature of technology use, many young Information Systems (IS) clients are not familiar with a different way of life, and thus, do not see the problem with heavy technology use. The assumption that constant technology use is a negative is an assumption that might not be consistent with outcomes.

In 1996, the American Psychological Association (APA) first considered adding Internet addiction as a psychiatric disorder, but opted against it, largely because there is no substance involved (Augenbraun, 2014). According to the APA, an addiction is "a condition in which the body must have a drug to avoid physical and psychological withdrawal symptoms" (American Psychological Association, 2014). Interdisciplinary researchers have failed to come to consensus on the authenticity of internet addiction. A major reason for this is the split in semantics over internet addiction and problematic internet use (Yellowlees \& Marks, 2007). However, most agree there is a negative aspect associated with smartphone, and more specifically, SNS use. While acknowledging the negative connotation of addiction, this paper will continue to use the term addiction, as that is the most understood current term used for the phenomena across disciplines, despite no formal clinical or psychiatric diagnosis.

Despite the associated negative sentiment, of people aged 18-29 years old, 89\% are SNS members and $67 \%$ of those access SNSs via a mobile phone (Pew Research Center, 2014). This group is composed of people raised completely engrossed in the use of technology, referred to as digital natives (Prensky, 2001). Beyond just digital natives, $74 \%$ of all internet users claim to use a SNS (Pew Research Center, 2014). The ubiquitous use of technology is clear; however, research on technology addiction assumes that constant use is a problem. The assumption that technology use is a negative is the focus of this research. The use of a delivery system (SNS) to effectively connect people and share information is the crux of the informing science framework. Arguably, Facebook is damaging social relationships, but those that use it claim more close personal relationships with others than those that do not use the sites (Pew Research Center, 2014). Knowing where to draw the line between addiction and dependence, or even frequent use, has not been thoroughly investigated in the SNS context.

A key feature of addiction is the impact the abuse has on the life of the addicted. One way of gauging the impact is by assessing quality of life. There has been a call for IS research to study the relationship between IS usage and quality of life (Lee, Kim, Choi, Lee, \& Im, 2005). This research takes the perspective of the IS client. If IS clients do not see frequent use of Facebook as a problem, it is arguably not something that can, or possibly should, be changed. It is well known that the first step 
of dealing with an addiction is determining there is a problem (Alcoholics Anonymous Publishing, 1952).

This research seeks to understand the relationship between the IS client's understanding of technology addiction, and how that impacts the IS client's overall life satisfaction. More specifically, this research contributes to grow the interdisciplinary knowledge base by addressing the relationship between technology addiction and a broader impact on the individual's life. As the debate about technology use continues, this research offers another perspective on technology use outcomes. This also fills a gap by further addressing antecedents that lead to addictive behavior on SNSs. To make progress in reducing the dependence on SNSs, the first step is identifying if the IS client sees it as a problem. Instead, it might be a major paradigm shift in how people communicate and society is resisting the change by negatively defining it.

The remainder of this paper is arranged as follows. First, a review of literature outlines the addiction construct and appropriate antecedents, as well as satisfaction with life scales, and the informing science framework in prior research. Next, a model is developed based on five hypotheses concerning SNS addiction. The methodology explains the administration of a survey and statistical results are presented. Discussion of practical implications for research and practitioners follows. Finally, limitations and future research directions are outlined before concluding remarks.

\section{LITERATURE REVIEW}

\section{ADDICTION}

Technology use is often the ultimate goal of systems, as can be seen through two of the most successful models of the IS discipline: the Technology Acceptance Model (F. D. Davis, 1989) and the IS Success Model (DeLone \& McLean, 1992). The function of an Information Technology (IT) developer is to encourage use. One way to encourage continued use of IS is to get the user to form habits, which can moderate the relationship between intention to use an IS and actual usage (Limayem, Hirt, \& Cheung, 2007). While habit encourages use of technology, it can also create problems and lead to addiction (Limayem et al., 2007). Habit is often preceded by use and satisfaction, with satisfaction as the most influential predictor (Lankton, Wilson, \& Mao, 2010).

The negative side of technology has not been considered by many researchers throughout most of the history of technology, however it is becoming more relevant as the ubiquity of computers is realized (D’Arcy \& Gupta, 2014). Five negative IT related issues were recently identified: technostress, information overload, multitasking, addictions, and technology misuse (D'Arcy \& Gupta, 2014). These factors relate to how a delivery system's (technology's) impact on IS clients who are trying to receive information. They all suggest technology is having a negative impact on the information client. Also, these factors often overlap (D'Arcy \& Gupta, 2014); however, this research focuses on the independent concept of addiction within the realm of negative IS.

The term addiction has not been clearly defined across disciplines (Vaghefi \& Lapointe, 2014). In psychology, addiction usually refers to ingestion of and dependence on a substance (Charlton \& Danforth, 2007), and is preceded by dependence (American Psychological Association, 2014).

The only addiction that does not involve a substance that is recognized by the Diagnostic and Statistical Manual of Mental Disorders, Fifth Edition (DSM-V), is pathological gambling (Young, 1998). Technology is not an ingestible substance, and therefore some are unwilling to claim the addiction state, instead terming it simply as the overuse of IT (Vaghefi \& Lapointe, 2014). The terminology debate divides researchers, some argue for addiction (Kuss, Griffiths, \& Binder, 2013; Young, 1998), while others argue that it is just problematic use (Charlton \& Danforth, 2007; Yellowlees \& Marks, 2007). Currently, the APA considers Internet Gaming Disorder, the only online related disorder considered, as a condition for further study and encourages research and debate about this phenomenon 
(American Psychiatric Association, 2014). In the meantime, the idea of SNS addiction has not been researched enough to warrant further classification in the DSM-V (Augenbraun, 2014).

Addiction can be broken into a mental and physical aspect (Vaghefi \& Lapointe, 2014). The mental aspect might include individual characteristics of the IS clients such as internal differences of each person (Vaghefi \& Lapointe, 2014). The physical aspect might be features of the substance itself, or external features of a person's social network (Vaghefi \& Lapointe, 2014). The most common mental dimensions of addiction are harm and inability to self-regulate (LaRose, Lin, \& Eastin, 2003; Vaghefi \& Lapointe, 2014). Harm might include conflicts at home, poor work or academic performance, or even depression (Zwanenburg, 2013). Inability to self-regulate means once a person begins using a system, the person is unable to stop, even if the person wants to stop. An implied third element is frequent use of the technology.

Like practice, this phenomenon is also termed many different things in research. Some authors define addiction as dependency, but also go further and add the debilitating feature of addiction (Li, Guo, \& Sun, 2012; Park, 2005). Others include dependency but also add excessive use (Vaghefi \& Lapointe, 2014). Some include excessive use in the definition of dependency, and others use addiction and dependency interchangeably (Thadani \& Cheung, 2011). One researcher uses the term "unregulated media usage" because the term addiction implies the need for a cure (LaRose et al., 2003). Still others refer to the whole phenomenon as Problematic Internet Use (PIU) instead of either addiction or dependency (R. A. Davis, Flett, \& Besser, 2002).

The distinction between terms might be most noticeable in connotation. Beyond formal APA definitions, addiction has a very negative cultural connotation, often associated with substance-abuse, and often encourages thoughts of harm to society or loved ones. Dependency is a term that encourages thoughts of weakness for the user, almost equally blaming the substance or behavior and the actor. Problematic use is a much softer term that gives the impression the behavior can easily be reversed or righted.

A related research area is to addiction is habit, which is often a predictor of addiction (e.g. LaRose et al., 2003; Turel, 2014; Wang, Lee, \& Hua, 2015). Habit is repeated activity resulting from an IS client learning to do something (Limayem et al., 2007). Over time, the habit becomes uncontrollable by the user and becomes problematic, or possibly an addiction (Wang et al., 2015). One research team found that enjoyment of using a social network can lead to both a good and bad habit (Turel \& Serenko, 2012). A bad habit could be termed an addiction according to the authors (Turel \& Serenko, 2012).

Prior research on addiction and technology considers SNS use as an antecedent to smartphone addiction (Salehan \& Negahban, 2013). Further research shows that SNS use is a stronger predictor of smartphone addiction than even gaming (Jeong, Kim, Yum, \& Hwang, 2016). Therefore, SNS use is related to multiple technologies and addiction, suggesting it is common to many types of IS clients.

In summary, the term addiction is loosely defined in research; thus, this research draws on literature using all similar terms. Generally, addiction has a very negative connotation. It includes an impact on personal life as well as an inability to change behaviors. Satisfaction or enjoyment with the technology often correlates with a reason people become addicted in the first place. While researchers debate semantics, very few directly ask actual IS clients about their own perceptions of technology addiction or habit.

\section{SATISFACTION WITH LIFE}

Addictions have a negative impact on those that are addicted. This can include an impact on social relationships, work or school performance, or bodily harm due to texting and driving (Vaghefi \& Lapointe, 2014). The impact of technology on use outcomes has been measured; however, little research has focused on overall satisfaction with life and technology (Choi, Lee, Im, \& Kim, 2007). This is an important area of research because technology is now ubiquitous (Lee et al., 2005). 
In the broad sense, technology is often assumed to improve the quality of life. Technology helps solve simple problems such as getting from one place to another. It also solves more complex problems, such as difficult mathematical equations or intercontinental communication. The advancement of technology is usually regarded as progress, and as a result, IS clients adopt the newest technological innovation as an improvement. Sometimes technology adoption creates more problems, such as the prevalence of automobiles has negative impacts on the environment and on people's health; however, many people would say that automobiles improve overall quality of life.

Per psychology literature, quality of life can be evaluated overall or in specific domains, which unite to make an individual life. Some domains include family, work, friends, leisure, finance, and oneself (Techatassanasoontorn \& Tanvisuth, 2010). Some argue that these individual domains combine to impact overall life satisfaction, termed a vertical or bottom-up spillover (Lee et al., 2005;

Techatassanasoontorn \& Tanvisuth, 2010). Similarly, these domains might not be mutually exclusive causing horizontal spillovers (Techatassanasoontorn \& Tanvisuth, 2010). For example, family life might influence a person's leisure life either negatively or positively, causing the quality of life in one domain to impact the other domain.

A relatively small amount of research has focused on either the domain specific approach or the overall approach to satisfaction with life in IS. The relationship between certain individual domains and overall satisfaction with mobile data services can have a positive impact, particularly if the IS client is satisfied (Lee et al., 2005). Moreover, mobile data services can impact many different domains of life simultaneously (Choi et al., 2007). Considering overall quality of life, the impact of technology can best be assessed in communities that are new to technology advancements. For instance, in Thailand, a study evaluating the impact of computers on socio-economically disadvantaged people found that, overall, quality of life is improved with computers (Techatassanasoontorn \& Tanvisuth, 2010). Recent research indicates that using a SNS more regularly can positively increase satisfaction with life at a university (Petersen \& Johnston, 2015).

Contrastingly, the impact of internet communication on well-being of an individual can be negative for adolescents (Valkenburg \& Peter, 2007). Interestingly, the same study indicates a tendency to talk to strangers can make the relationship positive (Valkenburg \& Peter, 2007). This finding suggests that communication with new people might have an impact on the value of internet communications in the eyes of adolescents. Some research addresses the relationship between smartphone addiction and satisfaction with life, finding support for the relationship when mediated by stress (Samaha \& Hawi, 2016). Findings indicate no direct relationship between smartphone addiction and satisfaction with life (Samaha \& Hawi, 2016). Other research indicates when people first adopt the internet, life satisfaction increases (Lissitsa \& Chachashvili-Bolotin, 2016).

For technology, the overall satisfaction with life is important because happiness refers to total satisfaction (Diener, Emmons, Larsen, \& Griffin, 1985). Importantly, technology is a part of every aspect of life and not easily split into unique domains (Lee et al., 2005). For instance, SNSs are usually comprised of work and social contacts, historical and present contacts, and intimate and superficial contacts. Most technological systems are no longer used for only one task (Lee et al., 2005).

In coordination with the ubiquity of technology, younger generations, i.e. digital natives, have never lived without technology (Vodanovich, Sundaram, \& Myers, 2010). Those that learn technology as adults instead of being born into it, are called digital immigrants, despite the fact that they may be very skilled with technology (Vodanovich et al., 2010). As the number of digital natives begins to outpace the number of digital immigrants, technology will have a greater impact on overall satisfaction with life.

\section{THE INFORMING SCIENCE FRAMEWORK AND SOCIAL NETWORK SITES (SNSS)}

The informing science framework (Cohen, 1999) revolves around understanding communication of information. The discipline focuses on information senders (delivery system), receivers (client), and 
the tools that help pass this information (delivery system) (Gill \& Cohen, 2009). In this research, the relevant delivery system is the SNS, which is trying to enable IS clients to connect with each other and share personal and public information. SNSs include websites that are communities meant to allow IS clients to interact in a social way, mimicking real-world social networks.

The most prevalent SNS in the United States is Facebook (Pew Research Center, 2014). Research on Facebook in all social sciences falls into five main categories: descriptive analyses of IS clients, motivations for use, identity presentation, the role of Facebook in social interactions, and privacy and information disclosure (R. E. Wilson, Gosling, \& Graham, 2012). Most research focuses on the role of Facebook in social interactions and descriptive analyses (R. E. Wilson et al., 2012). The Wilson et al. (2012) comprehensive literature review does not specifically discuss the relationship of habit, problematic use, or addiction, proving the newness of the area of study. Limited current research argues one of three things: a person can be addicted to an SNS, use of an SNS can lead to other addictions, or SNS use can have an impact on overall life.

The relationship between addiction, dependency, or habit with SNSs has not been studied significantly, even though some argue that social network addictions is one of the most relevant addictions (Zwanenburg, 2013). The research that exists often finds addiction effects. For instance, social network dependency is positively related to habit formation on SNSs (Thadani \& Cheung, 2011). Turel (2014) found a relationship between habit and addiction for Facebook users, and ultimately these led to discontinuance intentions mediated by guilt feelings and self-efficacy to discontinue. Facebook has also been associated with both good and bad habits in IS clients (Turel \& Serenko, 2012). These studies, taken together, indicate that SNSs can lead to a frequent use that may or may not be desirable for the IS client, and that desirability might change over time as the user becomes more engrossed in the SNS.

The direct role of SNS in forming other addictions has also been studied. The use of social networks can lead to general internet addiction (Kuss et al., 2013). Similarly, one study found that mobile phone addiction was positively related with increased SNS use (Salehan \& Negahban, 2013). These studies explain a broader addiction than SNS use by using SNS frequency of use as indicators.

Whether or not SNS use is an addiction, the impact of SNS on life outcomes is certainly important, however minimally researched. Some SNS clients feel that the social network is a burden because they are required to give social support to others on SNSs (Maier, Laumer, Eckhardt, \& Weitzel, 2014). This is a negative impact on life satisfaction as a result of SNS use. Facebook can also make IS clients feel more or less related to other individuals (Sheldon, Abad, \& Hinsch, 2011). On the positive side, some use a SNS to stay in touch with old friends (Johnson, 2008). Many people use SNSs to help form positive impressions of themselves to their peers (DiMicco \& Millen, 2007). Like most technology, SNSs were developed to help solve a problem, such as communicating with others, which has turned into a negative for some IS clients.

\section{HYPOTHESIS DEVELOPMENT}

Overall life satisfaction, as impacted by SNS addiction has not been extensively explored in the IS literature. The role of SNSs (delivery systems) in the ability to communicate information effectively between the information environment and the IS client is under studied. This research focuses on how the relationship between the IS client and the delivery system to understand life impacts. Based on the many definitions previously offered for technology addiction, for this research, addiction to SNS refers to extensive use of an SNS that the user is unable to stop using, and is beginning to have negative impacts for the IS client. The term addiction is used because it is the most prevalent term across all research; however, this research recognizes that it is a particularly negative connotation that might be interchangeable with dependence, problematic use, or bad habit. To understand the relationship between how IS clients perceive SNS (delivery system) addiction and overall life satisfaction (of the IS client), the research model in Figure 1 is proposed and elaborated on below. 


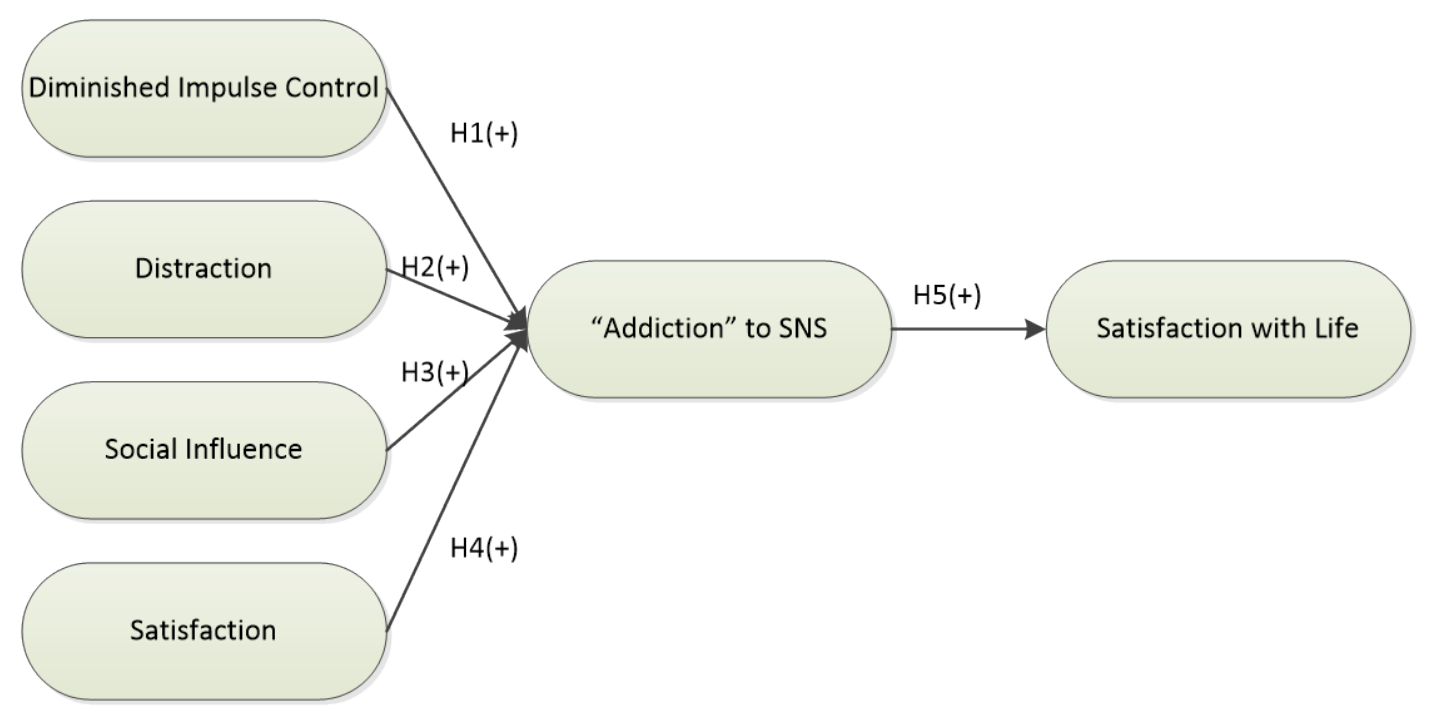

Figure 1. Proposed research model

Diminished impulse control refers to an inability to suppress feelings to stop using a SNS if the user wishes (Turel, 2014). Diminished impulse control was developed as part of the Online Cognition Scale (OCS) (R. A. Davis et al., 2002). It is similar to the discontinuance self-efficacy construct developed elsewhere (Turel, 2014). One of the fundamental ideas of addiction is that the person is unable to change behaviors, even though they want to change. These two constructs have been proven to correlate with problematic internet use (R. A. Davis et al., 2002) and addiction (Li et al., 2012; Turel, 2014). If a person is addicted to something, in this case an SNS, then the person will feel compelled to continue using it, even if it is causing problems. This leads to hypothesis 1 :

H1: Diminished impulse control will positively relate to SNS addiction.

Distraction is the inability to focus on the things a person intends (R. A. Davis et al., 2002). Distraction is negative, or harmful, because it sidetracks IS clients from productivity or efficiency when trying to accomplish a task. Distraction has been shown to positively correlate with problematic internet use (R. A. Davis et al., 2002) and addiction (Li et al., 2012). Distraction hinders progress, and as a result most people try to avoid distraction. If a person is addicted to a site, it is reasonable that this person is distracted by the SNS, which is causing negative impact. Hypothesis 2 reflects this relationship:

H2: Higher distraction will positively relate to SNS addiction.

The extent that a person believes important contacts want them to use a SNS is referred to as social influence (Venkatesh, Morris, Davis, \& Davis, 2003). Other research has used the idea of social comfort to incorporate how the IS client feels around others on a SNS (R. A. Davis et al., 2002). While similar, the former is more relevant because the person is likely to use a SNS only if there are others on the site with whom the person already associates. If people feel pressured to join a SNS to appease others, they are likely to continue to using the site frequently, developing into addiction. The relationship between social influence and SNS addiction is addressed in hypothesis 3:

H3: Greater social influence will positively relate so SNS addiction.

The final characteristic of addiction in the proposed model is satisfaction with the SNS. Satisfaction with a site stems from continuance research and is an evaluation a person makes about the attitude of using the SNS (Bhattacherjee, 2001). Satisfaction was the most influential indicator of habit in a study of worldwide web usage (Lankton et al., 2010), and is also positively associated with habit in the context of Facebook (Turel, 2014). In general, higher usage rates of SNS relates to higher satisfaction (Sheldon et al., 2011). If a person is going to form an addiction to a site, there must be fre- 
quent usage. If there is going to be frequent usage, the person must first have a reason to use the site. This reason is broadly termed satisfaction. This relationship is formally stated in hypothesis 4:

H4: Increased satisfaction with the SNS will positively relate to SNS addiction.

Finally, satisfaction with life is an important construct to understand how technology is impacting the IS client. The distinction made between the offline and online life is becoming harder for young people to make (Subrahmanyam \& Kraut, 2000). Some people feel that the use of technology in general is enhancing the way we communicate and relate to people, while others see it as deteriorating human relationships (Sheldon et al., 2011). Research on this topic is split, some finding a correlation with satisfaction and others not. One study indicates that greater satisfaction with life relates to less problematic Facebook use for the IS client (Satici \& Uysal, 2015). Contrastingly, college students that observe others actions on Facebook are less likely to be depressed (Tandoc, Ferrucci, \& Duffy, 2015). Further, one study found correlation between overall satisfaction and dissatisfaction when using a SNS (Sheldon et al., 2011).

Given that research on this topic is split, this research takes the psychological perspective that addiction has a negative impact on life satisfaction, as reflected in the definition of addiction for this research. Traditional substance addictions have a negative impact on overall quality of life (Laudet, 2011). Conversely, if a person meets the requirements for current definitions of addiction, but there is no relationship with satisfaction with life, then the addiction construct is either poorly labeled or not as negative as often discussed. Working from the assumptions of society, this research argues that there is a negative relationship between SNS addiction and satisfaction with life. Hypothesis 5 expresses this:

H5: SNS addiction will negatively relate to satisfaction with life.

\section{RESEARCH METHODOLOGY}

To test the model presented, a survey of undergraduate students at a large university in the southwestern United States was conducted. Undergraduate students represent a good sample for this survey because they are highly active on Facebook, an SNS (Rainie, Kiesler, \& Madden, 2013). Those between the ages of 16 and 24 now spend more than a day online per week (Luckerson, 2015). The general age of an undergraduate student is also within the range of digital natives, who are the upcoming generation to form opinions on technology.

Operationalization of the constructs of the model were contextualized from previous measures. Respondents were provided a 7-point Likert scale ranging from strongly disagree to strongly agree (see Appendix). The Online Cognition Scale was developed to evaluate IS client opinions of problematic internet use (R. A. Davis et al., 2002). Diminished impulse control and distraction were adopted from the Online Cognition Scale and modified to reflect the context of this study. Social influence was adopted from the well-tested Unified Theory of Acceptance and Use Technology measures (Venkatesh et al., 2003). Satisfaction was modified from the IS Continuance Model (Bhattacherjee, 2001). The addiction measure was also adopted from a previous study of technology dependence (Shu, Tu, \& Wang, 2011). This scale was used similarly as an antecedent to an outcome variable that focuses on human "attitudes, thoughts, behavior, and psychology" (Shu et al., 2011, p. 924); therefore, this particular measure of addiction is tested in a similar context.

The Satisfaction With Life Scale (SWLS) was developed to measure overall satisfaction with life internally by the respondent (Diener et al., 1985). There are two important distinctions from other measures of life satisfaction: it is not a judgment imposed by external parties on another's life, and it is an overall measure of satisfaction, not just satisfaction with one element or aspect of life (Diener et al., 1985). It is a timeless, parsimonious scale for determining general satisfaction with life.

This survey was administered online via Qualtrics Survey software. Six classes offered the survey for course credit, which encouraged ample attention to the survey. There were 854 potential respondents 
in the sampling frame, 589 responded, resulting in a $68.97 \%$ response rate. Of the responses, only participants that reported Facebook as the primary social media tool were kept for analysis to ensure consistency. Ten surveys were omitted due to lack of variance across the entire survey (i.e. selecting all 1's or all 7's). This resulted in 413 usable responses for analysis. Almost $90 \%$ of respondents are digital natives. Complete demographics of the sample are listed in Table 1.

Table 1. Demographics

\begin{tabular}{|l|l|l|l|l|l|l|l|l|}
\hline \multicolumn{4}{|l|}{ Gender } & \multicolumn{4}{l|}{ Age } & \multicolumn{3}{l|}{ Academic Status } \\
\hline Male & 216 & $52.43 \%$ & $\mathbf{1 8 - 2 1}$ & 180 & $43.69 \%$ & Freshman & 13 & $3.16 \%$ \\
\hline Female & 196 & $47.57 \%$ & $\mathbf{2 2 - 2 5}$ & 138 & $33.50 \%$ & Sophomore & 66 & $16.02 \%$ \\
\hline Major & & $\mathbf{2 6 - 2 9}$ & 42 & $10.19 \%$ & Junior & 233 & $56.55 \%$ \\
\hline Business & 382 & $92.50 \%$ & $\mathbf{3 0 - 3 3}$ & 24 & $5.83 \%$ & Senior & 93 & $22.57 \%$ \\
\hline Other & 30 & $8.50 \%$ & $\mathbf{3 4 +}$ & 28 & $6.80 \%$ & Graduate & 7 & $1.70 \%$ \\
\hline
\end{tabular}

\section{RESULTS}

The first step of the analysis was Exploratory Factor Analysis (EFA) to determine if factors of a construct are loading together on one construct. This was performed with a varimax rotation (see Appendix). Upon closer review, limited items were removed due to poor adaptation to the context. All factors load higher on their expected construct than on any other, indicating convergent validity (Hair, Black, Babin, \& Anderson, 2010). Further, all latent variable Average Variances Explained (AVEs) should exceed 0.5, as indicated in Table 2 (Henseler, Ringle, \& Sinkovics, 2009). The reliability of constructs shows how consistent the measurement of the construct is and should have a Cronbach's Alpha greater than 0.7 and composite reliability greater than 0.8 (Nunnally \& Bernstein, 1994). Reliability calculations are shown in Table 2.

Table 2. Measurement model summary

\begin{tabular}{|c|c|c|c|c|c|c|c|c|c|}
\hline & \multirow{2}{*}{$\begin{array}{l}\text { Cronbach } \\
\alpha\end{array}$} & \multirow{2}{*}{$\begin{array}{l}\text { Composite } \\
\text { Reliability }\end{array}$} & \multirow[b]{2}{*}{ AVE } & \multicolumn{6}{|c|}{ Factor Correlations } \\
\hline & & & & SWL & DIC & SAT & ADD & DIS & SI \\
\hline$\overline{\text { SWL }}$ & 0.858 & 0.893 & 0.626 & 0.791 & & & & & \\
\hline DIC & 0.966 & 0.971 & 0.810 & -0.009 & 0.900 & & & & \\
\hline SAT & 0.950 & 0.960 & 0.799 & 0.196 & 0.167 & 0.894 & & & \\
\hline ADD & 0.929 & 0.944 & 0.740 & 0.110 & 0.607 & 0.480 & 0.860 & & \\
\hline DIS & 0.912 & 0.938 & 0.792 & 0.018 & 0.554 & 0.257 & 0.512 & 0.890 & \\
\hline SI & 0.869 & 0.919 & 0.792 & 0.172 & 0.216 & 0.390 & 0.400 & 0.172 & 0.890 \\
\hline
\end{tabular}

Given the reliability and validity of the constructs, next the risk of common method bias needs to be eliminated. Common method bias is the concern that something external to the variables is responsible for the results (Podsakoff, MacKenzie, Lee, \& Podsakoff, 2003). Harman's single factor test is often used to indicate common method bias (Podsakoff et al., 2003). Specifically, all items were evaluated with unrotated factor analysis, with the specification of one factor. The single factor ex- 
plained only $36.00 \%$ of the variance, which is well below half of the variance, suggesting there is little concern of common method bias (Podsakoff et al., 2003).

Next, Smart PLS 2.0 (Ringle, Wende, \& Will, 2005) allows analysis of the structural model. Structural Equation Modeling (SEM) is ideal because it accounts for measurement error of the entire model concurrently (Hair et al., 2010). The variance explained by the model $\left(\mathrm{R}^{2}\right)$ should be greater than 0.3 to indicate explanatory power (Hair et al., 2010). The regression weights and $\mathrm{R}^{2}$ values are shown in Figure 2. Hypotheses 1, 2, 3, and 4 are all significant at the 0.001 level. Hypothesis 5 is not significant, meaning there is no significant relationship between addiction to a SNS and satisfaction with life. Overall, the antecedents of addiction represent $55.6 \%$ of the variance in the construct. Only $1 \%$ of the variance in satisfaction with life can be explained by addiction to the SNS.

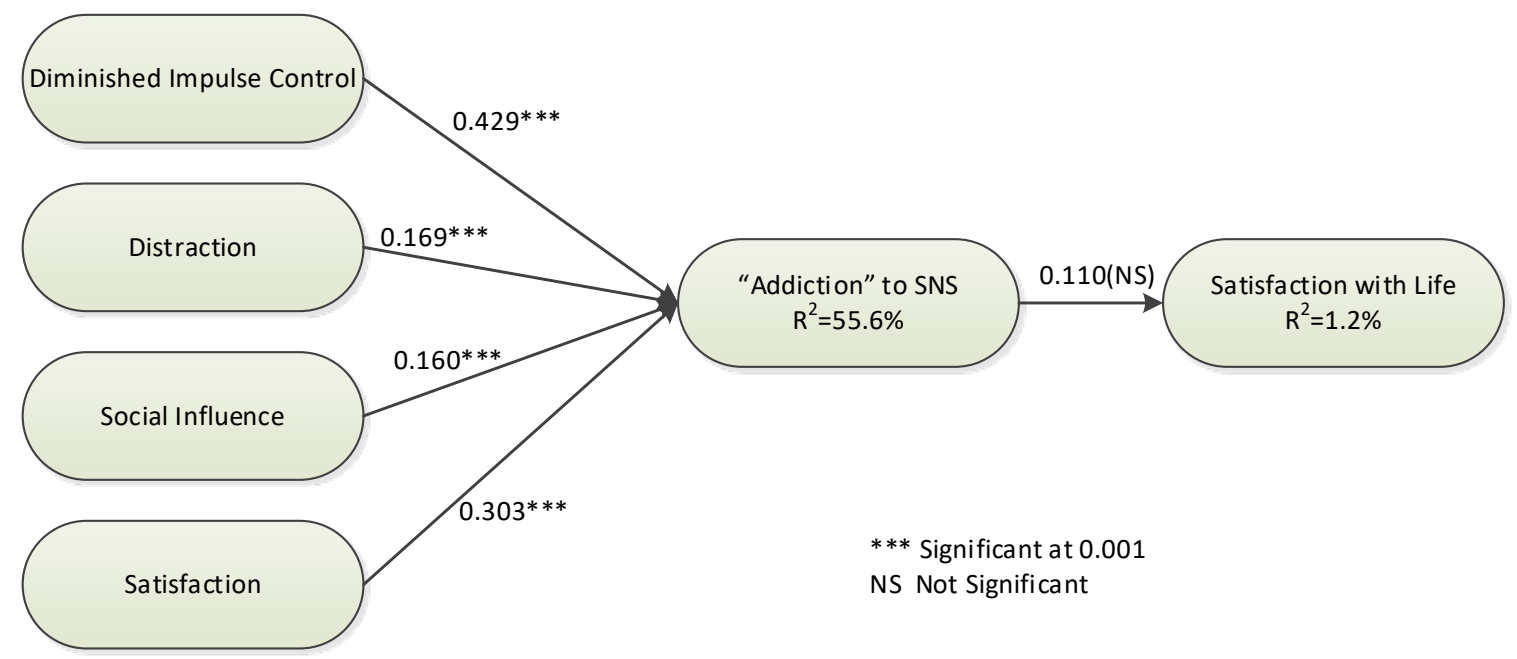

Figure 2. Structural equation model

\section{DISCUSSION}

Hypotheses 1 through 4 are all significant. This simply indicates that the prior research on addiction and technology use has clearly identified antecedents to addiction. Specifically, diminished impulse control is related to addiction signaling an IS client's inability to stop using the site. Secondly, the SNS is distracting, and consequently related to addiction, presuming people prefer not to be distracted when trying to accomplish a task. The relationship between social influence and addiction implies people are more likely to heavily use a SNS if others think it is important. Finally, satisfaction with the SNS relates to addiction to the SNS.

The addiction construct, for this research, was borrowed from previous research. The connotation of the prior research implies that addiction is a problem. However, hypothesis 5 shows that what is called addiction is not significantly related to satisfaction with life. The non-significant relationship and virtually non-existent $\mathrm{R}^{2}$ indicates that the negative relationship is not actually manifested as a negative to the digital native IS clients of the technology. Instead, the respondents meet the criteria for what research terms "addiction" but do not correlate this with a negative impact on satisfaction with life. As outsiders, researchers term the phenomenon of heavy use or dependence on technology as a negative, when digital natives are actually not seeing the same impact.

This research does not find a significant relationship between SNS addiction and satisfaction with life, which contributes to the growing dialogue of negative technology use. This is a key revelation for both researchers and practitioners in understanding the IS client of the future. Future research should consider technology integration in the social life as a new norm instead of a problem. Specifically, these finding are informative within the informing science framework, the ability to help communication among IS clients through the delivery system. Notably, the delivery system is effectively 
connecting the informing environment and the IS client, suggesting it is working. Considering these ideas from a transdisciplinary perspective can guide future research.

For organizations, understanding how IS clients view their own technology uses is important in understanding how to relate to the customer. Further focus on the value that SNS technology brings to IS clients, instead of the change it causes, might relate better to digital native customers. While digital immigrants might see significant problems with heavy technology use, digital natives grew up constantly interacting with technology. Instead of a problem, this is just a way of life for digital natives. Internet addiction, when first being discussed, was absolutely labeled as a concern (i.e. Pinnelli, 2002); however, the pervasiveness of online access might be shifting this negativity. One researcher suggests that the combination of the digital native generation and ubiquity of technology is signaling a paradigm shift for computer use (Vodanovich et al., 2010). Technology use is undergoing a paradigm shift from use when needed, to constant use.

This research is not without limitations; however, they can easily be improved in future research. The first limitation of this study is the use of one specific SNS. Facebook continues to have significant membership; however, it is becoming less important to younger audiences (Saul, 2014). While SNS addiction has been related to other technology addictions (i.e. Salehan \& Negahban, 2013), this might indicate that it would be good to perform a similar analysis using a different SNS, or broaden the scope to a more general technology.

Secondly, the sampling frame for this analysis used a convenience sample. Broadening the variation of respondents beyond mostly business undergraduate students might make the results more generalizable. Similarly, satisfaction with life might be difficult for an undergraduate to accurately determine at a young age. It is argued that younger IS clients do not yet realize the implications of their online profiles because the future is seemingly far away (Wolpe, 2015). Despite this, it is important that the scale used is purposefully judged by the individual and not outside actors (Diener et al., 1985). This research could also benefit from a comparison of digital natives and digital immigrants, who, as reflected in society, may view addiction to SNS as having different impacts on life satisfaction.

Finally, the satisfaction with life construct is intended to be broad due to the ubiquity of technology; however, further analysis into other dimensions and the potential of vertical and horizontal spillovers might be warranted in future research. It could also be beneficial to consider other outcome variables beyond satisfaction with life, to properly measure impacts heavy SNS use is having on actual life outcomes.

\section{CONCLUSION}

So-called technology addiction is a growing phenomenon. People become more dependent on the technology around them every day. Research shows that "addiction" is existent among young people on SNSs; however, the impacts of this "addiction" are not truly understood. Addictions, by definition, cause harm to the user; however, in this research it is clear that frequent use of an SNS to the point of being labeled an addiction does not significantly correlate with satisfaction with life. Instead of a true problem, digital natives see no impact of frequent SNS use on overall life satisfaction. This suggests that people are using the technology (delivery system) to receive and send information without seeing the use as negative, or at least as negative as media suggests. This research establishes that people meet certain prior accepted conditions for addiction, and also statistically shows common measures of addiction are related. The fact that these antecedents do not relate to satisfaction with life is a clear indicator that the terminology associated with frequent SNS use is overly negative. Prior literature has assumed that "addiction" is a negative. Instead of an addiction, this signals a paradigm shift concerning how people interact with the world and those around them. 


\section{REFERENCES}

Alcoholics Anonymous Publishing. (1952). Alcoholics Anonymous. Retrieved from http://www.aa.org/pages/en US/what-is-aa

American Psychiatric Association. (2014). DSM-5 Development. Retrieved from http://www.dsm5.org/Pages/Default.aspx

American Psychological Association. (2014). Addictions. Retrieved from http://apa.org/topics/addiction/index.aspx

Augenbraun, E. (2014, August 22). How real a risk is social media addiction? Retrieved from http://www.cbsnews.com/news/how-real-a-risk-is-social-media-addiction/

Bhattacherjee, A. (2001). Understanding information systems continuance: An expectation-confirmation model. MIS Quarterly, 25(3), 351-370.

Charlton, J. P., \& Danforth, I. D. W. (2007). Distinguishing addiction and high engagement in the context of online game playing. Computers in Human Behavior, 23(3), 1531-1548. Retrieved from https://doi.org/10.1016/i.chb.2005.07.002

Choi, H., Lee, M., Im, K., \& Kim, J. (2007). Contribution to quality of life: A new outcome variable for mobile data service. Journal of the Association for Information Systems, 8(12), 598-618.

Cohen, E. B. (1999). Reconceptualizing information systems as a field of the Transdiscipline Informing Science: From ugly duckling to swan. Journal of Computing and Information Technology, 7(3), 213-219.

D'Arcy, J., \& Gupta, A. (2014). Reflecting on the "dark side" of information technology use. Communications of the Association for Information Systems, 35, 109-118.

Davis, F. D. (1989). Perceived usefulness, perceived ease of use, and user acceptance of information technology. MIS Quarterly, 13(3), 319-340.

Davis, R. A., Flett, G. L., \& Besser, A. (2002). Validation of a new scale for measuring problematic internet use: implications for pre-employment screening. Cyberpsychology \& Behavior, 5(4), 331-45.

DeLone, W. H., \& McLean, E. R. (1992). Information systems success: The quest for the dependent variable. Information Systems Research, 3(1), 60-95. Retrieved from https://doi.org/10.1287/isre.3.1.60

Diener, E., Emmons, R. A., Larsen, R. J., \& Griffin, S. (1985). The satisfaction with life scale. Journal of Personality Assessment, $49(1), 71-75$.

DiMicco, J. M., \& Millen, D. R. (2007). Identity management: Multiple presentations of self in Facebook. In Proceedings of the 2007 International ACM Conference on Supporting Group Work (pp. 383-386). New York: ACM.

Gill, T. G., \& Cohen, E. (2009). Foundations of informing science: 1999-2008. Santa Rosa, CA: Informing Science Press.

Hair, J. F. J., Black, W. C., Babin, B. J., \& Anderson, R. E. (2010). Multivariate data analysis (7th ed.). Upper Saddle River, NJ: Prentice Hall.

Henseler, J., Ringle, C. M., \& Sinkovics, R. R. (2009). The use of partial lease squares path modeling in international marketing. Advances in International Marketing, 20(2009), 277-319. Retrieved from https://doi.org/10.1108/S1474-7979(2009)0000020014

Jeong, S.-H., Kim, H., Yum, J.-Y., \& Hwang, Y. (2016). What type of content are smartphone users addicted to? SNS vs. games. Computers in Human Behavior, 54, 10-17. Retrieved from https://doi.org/10.1016/i.chb.2015.07.035

Johnson, M. E. (2008). Information risk of inadvertent disclosure: An analysis of file-sharing risk in the financial supply chain. Journal of Management Information Systems, 25(2), 97-124. Retrieved from https://doi.org/10.2753/MIS0742-1222250205

Kuss, D. J., Griffiths, M. D., \& Binder, J. F. (2013). Internet addiction in students: Prevalence and risk factors. Computers in Human Behavior, 29(3), 959-966. Retrieved from https://doi.org/10.1016/j.chb.2012.12.024 
Lankton, N. K., Wilson, E. V., \& Mao, E. (2010). Antecedents and determinants of information technology habit. Information \& Management, 47, 300-307. Retrieved from https://doi.org/10.1016/i.im.2010.06.004

LaRose, R., Lin, C. A., \& Eastin, M. S. (2003). Unregulated internet usage: Addiction, habit, or deficient selfregulation? Media Psychology, 5(3), 225-253. Retrieved from https://doi.org/10.1207/S1532785XMEP0503 01

Laudet, A. B. (2011). The case for considering quality of life in addiction research and clinical practice. Addiction Science \& Clinical Practice, 6(1), 44-55.

Lee, M., Kim, J., Choi, H., Lee, D., \& Im, K. S. (2005). Contributing to quality of life: A new outcome variable for information technology in ubiquitous computing environments. SIGHCI 2005 Proceedings 1 (pp.85-89).

Li, Q., Guo, X., \& Sun, C. (2012). The shadow of microblogging use: Relationship between usage types and addiction. Proceedings of the $33^{\text {rd }}$ International Conference on Information Systems (pp. 1-11). Orlando, Florida.

Limayem, M., Hirt, S. G., \& Cheung, C. M. K. (2007). How habit limits the predictive power of intention: The case of information systems continuance. MIS Quarterly, 31(4), 705-737.

Lissitsa, S., \& Chachashvili-Bolotin, S. (2016). Life satisfaction in the internet age: Changes in the past decade. Computers in Human Behavior, 54, 197-206. Retrieved from https://doi.org/10.1016/j.chb.2015.08.001

Luckerson, V. (2015). Google blames bumans for accidents involving its self-driving cars. Retrieved from http://time.com/3854528/google-self-driving-cars-accidents/

Maier, C., Laumer, S., Eckhardt, A., \& Weitzel, T. (2014). Giving too much social support: Social overload on social networking sites. European Journal of Information Systems (February 2013), 1-18. Retrieved from https://doi.org/10.1057/ejis.2014.3

Nunnally, J. C., \& Bernstein, I. H. (1994). Pyschometric theory. New York: McGraw-Hill.

Park, W. K. (2005). Mobile phone addiction. Mobile Communications (pp. 253-272). London: Springer.

Petersen, C., \& Johnston, K. A. (2015). The impact of social media usage on the cognitive social capital of university students. Informing Science: The International Journal of an Emerging Transdiscipline, 18, 1-30. Retrieved from https://www.informingscience.org/Publications/2160

Pew Research Center. (2014). Social networking fact sheet. Retrieved from http://www.pewinternet.org/factsheets/social-networking-fact-sheet/

Pinnelli, S. (2002, June). Internet addiction disorder and identity on line: The educational relationship. Proceedings of the 2002 Informing Science + IT Education Conference, Cork, Ireland, 1259-1265. Retrieved from http://proceedings.informingscience.org/IS2002Proceedings/papers/Pinne088Inter.pdf

Podsakoff, P. M., MacKenzie, S. B., Lee, J.-Y., \& Podsakoff, N. P. (2003). Common method biases in behavioral research: A critical review of the literature and recommended remedies. The Journal of Applied Psychology, 88(5), 879-903. Retrieved from https://doi.org/10.1037/0021-9010.88.5.879

Prensky, M. (2001). Digital natives, digital immigrants. On the Horizon, 9(5), 1-6.

Rainie, L., Kiesler, S., \& Madden, M. (2013). Anonymity, privacy, and security online. Washington D.C. Retrieved from http://pewinternet.org/Reports/2013/Anonymity-online.aspx

Ringle, C. M., Wende, S., \& Will, A. (2005). SmartPLS 2.0. Hamburg, Germany: University of Hamburg.

Salehan, M., \& Negahban, A. (2013). Social networking on smartphones: When mobile phones become addictive. Computers in Human Behavior, 29(6), 2632-2639. Retrieved from https://doi.org/10.1016/i.chb.2013.07.003

Samaha, M., \& Hawi, N. S. (2016). Relationships among smartphone addiction, stress, academic performance, and satisfaction with life. Computers in Human Behavior, 57, 321-325. Retrieved from https://doi.org/10.1016/i.chb.2015.12.045

Satici, S. A., \& Uysal, R. (2015). Well-being and problematic Facebook use. Computers in Human Behavior, 49, 185-190. Retrieved from https://doi.org/10.1016/i.chb.2015.03.005

Saul, D. (2014). 3 million teens leave Facebook in 3 years: The 2014 Facebook Demographic Report. Retrieved from http://istrategylabs.com/2014/01/3-million-teens-leave-facebook-in-3-years-the-2014-facebookdemographic-report/ 
Sheldon, K. M., Abad, N., \& Hinsch, C. (2011). A two-process view of Facebook use and relatedness needsatisfaction: Disconnection drives use, and connection rewards it. Psychology of Popular Media Culture, 1(S), 2-15. Retrieved from https://doi.org/10.1037/2160-4134.1.S.2

Shu, Q., Tu, Q., \& Wang, K. (2011). The impact of computer self-efficacy and technology dependence on computer-related technostress: A social cognitive theory perspective. International Journal of Human-Computer Interaction, 27(10), 923-939. Retrieved from https://doi.org/10.1080/10447318.2011.555313

Subrahmanyam, K., \& Kraut, R. (2000). The impact of home computer use on children's activities and development. The Future of Children, 10(2), 123-144.

Tandoc, E. C., Ferrucci, P., \& Duffy, M. (2015). Facebook use, envy, and depression among college students: Is facebooking depressing? Computers in Human Behavior, 43, 139-146. Retrieved from https://doi.org/10.1016/i.chb.2014.10.053

Techatassanasoontorn, A. A., \& Tanvisuth, A. (2010). IS use and quality of life: A conceptualization and empirical investigation. AIS Transactions on Human-Computer Interaction, 2(2), 26-54.

Thadani, D. R., \& Cheung, C. M. K. (2011). Exploring the role of online social network dependency in habit formation. Proceedings of the 32nd International Conference on Information Systems (pp. 1-17). Shanghai.

Turel, O. (2014). Quitting the use of a habituated hedonic information system: A theoretical model and empirical examination of Facebook users. European Journal of Information Systems, 23(1), 1-16. Retrieved from https://doi.org/10.1057/ejis.2014.19

Turel, O., \& Serenko, A. (2012). The benefits and dangers of enjoyment with social networking websites. European Journal of Information Systems, 21(5), 512-528. Retrieved from https://doi.org/10.1057/ejis.2012.1

Vaghefi, I., \& Lapointe, L. (2014). When too much usage is too much: Exploring the process of IT addiction. Proceedings of the 47th Hawaii International Conference on System Sciences (pp. 4494-4503). IEEE. Retrieved from https://doi.org/10.1109/HICSS.2014.553

Valkenburg, P. M., \& Peter, J. (2007). Internet communication and its relation to well-being: Identifying some underlying mechanisms. Media Psychology, 9(1), 43-58. Retrieved from https://doi.org/10.1080/15213260709336802

Venkatesh, V., Morris, M. G., Davis, G. B., \& Davis, F. D. (2003). User acceptance of information technology: Toward a unified view. MIS Quarterly, 27(3), 425-478.

Vodanovich, S., Sundaram, D., \& Myers, M. (2010). Research commentary: Digital natives and ubiquitous information systems. Information Systems Research, 21(4), 711-723. Retrieved from https://doi.org/10.1287/isre.1100.0324

Wang, C., Lee, M. K. O., \& Hua, Z. (2015). A theory of social media dependence: Evidence from microblog users. Decision Support Systems, 69, 40-49. Retrieved from https://doi.org/10.1016/j.dss.2014.11.002

Wilson, J. (2014). Man treated for Google Glass addiction. Retrieved from http://www.cnn.com/2014/10/15/health/google-glass-addiction/index.html

Wilson, R. E., Gosling, S. D., \& Graham, L. T. (2012). A review of Facebook research in the social Sciences. Perspectives on Psychological Science, 7(3), 203-220. Retrieved from https://doi.org/10.1177/1745691612442904

Wolpe, D. (2015). Drunk mistakes posted on Facebook are forever. Retrieved from http://time.com/3838345/drunksocial-media-permanence/

Yellowlees, P. M., \& Marks, S. (2007). Problematic internet use or internet addiction? Computers in Human Behavior, 23(3), 1447-1453. Retrieved from https://doi.org/10.1016/i.chb.2005.05.004

Young, K. S. (1998). Internet addiction: The emergence of a new clinical disorder. Cyberpsychology \& Behavior, 1(3), 237-244.

Zwanenburg, S. P. (2013). Information technology addiction: Construct development and measurement. Proceedings of the $34^{\text {th }}$ International Conference of Information Systems (pp. 1-12). Milan. 


\section{APPENDIX: MEASUREMENT ITEMS, CFA AND EFA RESULTS}

\begin{tabular}{|c|c|c|c|c|c|c|c|}
\hline & & \multicolumn{6}{|c|}{ EFA } \\
\hline & Item & DIC & SAT & ADD & SWL & DIS & SI \\
\hline DIC6 & I can't stop thinking about the social network. & .897 & .021 & .193 & -.013 & .111 & .051 \\
\hline DIC8 & $\begin{array}{l}\text { My use of the social network sometimes seems } \\
\text { beyond my control. }\end{array}$ & .890 & .016 & .189 & -.033 & .125 & .003 \\
\hline DIC4 & $\begin{array}{l}\text { When I am not online, I often think about the } \\
\text { social network. }\end{array}$ & .883 & .054 & .229 & -.021 & .191 & .081 \\
\hline DIC7 & $\begin{array}{l}\text { Even though there are times when I would like to, } \\
\text { I can't cut down on my use of the social network. }\end{array}$ & .875 & .062 & .182 & -.036 & .157 & -.013 \\
\hline DIC5 & $\begin{array}{l}\text { The offline world is less exciting than what you } \\
\text { can do on the social network. }\end{array}$ & .855 & .020 & .166 & -.022 & .093 & .041 \\
\hline DIC3 & $\begin{array}{l}\text { People complain that I use the social network too } \\
\text { much. }\end{array}$ & .850 & .051 & .245 & .008 & .181 & .065 \\
\hline DIC2 & $\begin{array}{l}\text { When I am on the social network, I often feel a } \\
\text { kind of "rush" or emotional high. }\end{array}$ & .832 & .040 & .228 & .004 & .180 & .089 \\
\hline DIC1 & $\begin{array}{l}\text { I often keep thinking about the social network } \\
\text { well after I have logged off. }\end{array}$ & .773 & .059 & .188 & -.027 & .257 & .135 \\
\hline SAT2 & I am pleased with use of the social network. & .016 & .907 & .151 & .095 & .112 & .108 \\
\hline SAT3 & I am content with use of the social network. & .006 & .890 & .137 & .043 & .139 & .072 \\
\hline SAT1 & I am satisfied with use of the social network. & -.063 & .883 & .177 & .090 & .094 & .058 \\
\hline SAT4 & I am delighted with use of the social network. & .115 & .872 & .171 & .054 & .057 & .133 \\
\hline SAT5 & Using the social network meets my expectations. & .015 & .848 & .150 & .094 & .063 & .164 \\
\hline SAT6 & I feel fulfilled when using the social network. & .196 & .762 & .238 & .089 & -.010 & .188 \\
\hline ADD5 & $\begin{array}{l}\text { I have felt unable to connect when the social net- } \\
\text { work is unavailable. }\end{array}$ & .425 & .146 & .775 & .068 & .121 & .130 \\
\hline ADD2 & $\begin{array}{l}\text { It would be difficult to imagine my life without } \\
\text { the social network. }\end{array}$ & .358 & .211 & .763 & .040 & .147 & .151 \\
\hline ADD6 & The social network must be used to stay updated. & .272 & .243 & .759 & .033 & .128 & .090 \\
\hline ADD4 & $\begin{array}{l}\text { I have felt debilitated when unable to connect to } \\
\text { the social network. }\end{array}$ & .430 & .183 & .756 & .028 & .158 & .177 \\
\hline ADD1 & $\begin{array}{l}\text { The social network has replaced other major } \\
\text { communication devices for me. }\end{array}$ & .262 & .267 & .705 & .018 & .134 & .044 \\
\hline ADD3 & $\begin{array}{l}\text { I get a significant amount of information from } \\
\text { the social network. }\end{array}$ & .172 & .327 & .641 & .032 & .285 & .163 \\
\hline SWL3 & I am satisfied with my life. & -.080 & .027 & .006 & .868 & -.076 & .022 \\
\hline SWL2 & The conditions of my life are excellent. & -.044 & .108 & .057 & .830 & .045 & -.065 \\
\hline SWL1 & In most ways my life is close to my ideal. & -.007 & .083 & .025 & .802 & -.010 & .082 \\
\hline SWL4 & $\begin{array}{l}\text { So far I have gotten the important things I want } \\
\text { in life. }\end{array}$ & -.013 & .079 & .050 & .769 & .012 & .059 \\
\hline SWL5 & $\begin{array}{l}\text { If I could live my life over, I would change almost } \\
\text { nothing. }\end{array}$ & .044 & .048 & -.009 & .698 & -.005 & .127 \\
\hline
\end{tabular}




\begin{tabular}{|c|c|c|c|c|c|c|c|}
\hline & & \multicolumn{6}{|c|}{ EFA } \\
\hline & Item & DIC & SAT & ADD & SWL & DIS & SI \\
\hline DIS2 & $\begin{array}{l}\text { I sometimes use the social network to procrasti- } \\
\text { nate. }\end{array}$ & .107 & .124 & .159 & -.044 & .854 & .036 \\
\hline DIS3 & $\begin{array}{l}\text { I often use the social network to avoid doing un- } \\
\text { pleasant things. }\end{array}$ & .327 & .131 & .131 & -.006 & .844 & .044 \\
\hline DIS4 & $\begin{array}{l}\text { Using the social network is a way to forget about } \\
\text { the things I must do but don't really want to do. }\end{array}$ & .411 & .107 & .179 & -.002 & .787 & .038 \\
\hline DIS1 & $\begin{array}{l}\text { I find that I get on the social network more when } \\
\text { I have something else I am supposed to do. }\end{array}$ & .389 & .078 & .243 & .018 & .732 & -.006 \\
\hline SI2 & $\begin{array}{l}\text { People who are important to me think that I } \\
\text { should use the social network. }\end{array}$ & .094 & .227 & .188 & .060 & .070 & .863 \\
\hline SI1 & $\begin{array}{l}\text { People who influence my behavior think that I } \\
\text { should use the social network. }\end{array}$ & .108 & .173 & .200 & .104 & .062 & .846 \\
\hline $\mathrm{SI} 3$ & $\begin{array}{l}\text { My family members think that I should use the } \\
\text { social network. }\end{array}$ & .065 & .175 & .059 & .090 & -.025 & .825 \\
\hline
\end{tabular}

$D I C=$ Diminished Impulse Control, $S A T=S$ atisfaction, $A D D=A d d i c t i o n, S W L=$ Satisfaction With Life, DIS $=$ Distraction, SI=Social Influence

\section{BIOGRAPHY}

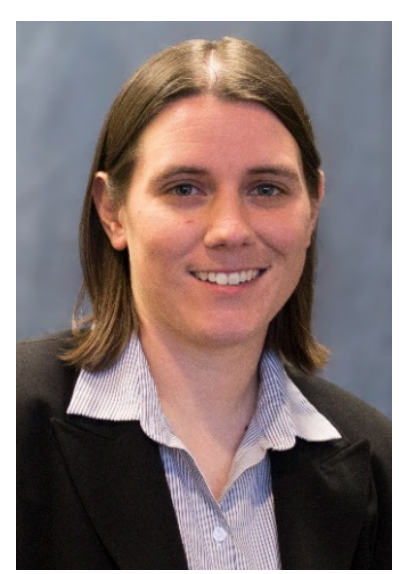

Natalie Gerhart, Ph.D. is an Assistant Professor of Information Systems at Creighton University. She received her Ph.D. from the Information Technology and Decisions Sciences department at the University of North Texas. She also holds an MBA from the University of Missouri-Columbia in Marketing Analytics and a Bachelor of Science degree from Truman State University in Management Information Systems and Marketing. Previously, she has published in MISQ Executive, Decision Support Systems, Journal of Computer Information Systems, and the Decision Sciences Journal of Innovate Education. Her research interests include decision stopping rules, human computer interaction (HCI), business intelligence and analytics (BI\&A), and social networking. 